\title{
Leptin and Adiponectin in the HIV Associated Metabolic Syndrome: Physiologic and Therapeutic Implications
}

\author{
Sotirios Tsiodras, MD and Christos Mantzoros, MD. \\ Division of Endocrinology, Diabetes and Metabolism, Beth Israel Deaconess Medical Center \\ Harvard Medical School, 02215
}

\begin{abstract}
Leptin and adiponectin represent two newly discovered adipose tissue derived hormones with important roles in energy homeostasis and insulin resistance. Their interrelations with the manifestations of the HIV associated metabolic syndrome and specific somatomorphic changes i.e. fat redistribution is reviewed. A synopsis of published studies is presented and the potential role of leptin and adiponectin is discussed. We have described an association of the HIV metabolic syndrome with a state of reduced insulin sensitivity due to adiponectin deficiency. The metabolic syndrome is also accompanied by leptin deficiency in lipoatrophic subjects and possibly by a leptin resistance state in lipohypertrophic patients. Adiponectin and / or leptin therapy in a manner similar to other leptin deficiency states may assist in the future management of such patients.
\end{abstract}

Key words: HIV, adipokine, adipocytokines, adiponectin, metabolic syndrome, insulin resistance

\section{INTRODUCTION}

Clinicians face the anxiety of HIV-1 patients with metabolic and morphological changes seen in association with their antiretroviral therapeutic regimens regarding potential long-term effects directly related to their therapy ${ }^{[1]}$. Recent studies have confirmed the association between the HIV combination of antiretroviral regimens, the metabolic syndrome and an increased risk for cardiovascular events ${ }^{[2,3]}$. Great uncertainty continues to exist regarding the definition as well as the exact pathophysiology of the HIV associated metabolic and morphologic changes. New theories suggesting potential mechanisms are published ${ }^{[4]}$ but there is still difficulty in understanding the full spectrum of the clinical entity ${ }^{[1,5]}$. Many of the endpoints examined during studies of the syndrome are shared by the general population and thus are subject to multiple confounding from genetic, environmental (including toxicity from the antiretrovirals) and other factors not specific to the HIV disease.

Adipose tissue derived hormones (adipokines) may play an important role in the pathogenesis of the HIV associated metabolic syndrome and they have been the focus of extensive research over the last few years. Two adipokines leptin and adiponectin have been the focus of the majority of the research efforts. In the current report we review available literature on leptin and adiponectin and their association with the development of phenotypic and/or metabolic changes in HIV infected subjects treated with HAART.
The HIV associated metabolic syndrome: Diabetes, glucose intolerance and insulin resistance were the first described manifestations ${ }^{[1,6]}$. They were soon followed by reports of dyslipidemia ${ }^{[7-11]}$ and body shape changes $^{[1,8,12-15]}$. The term "lipodystrophy" that was then used is probably not inclusive of the entire spectrum of manifestations. Hyperlactatemia and loss of bone mineral density were recognized subsequently, but there is uncertainty as to whether they are part of the same process. There is still no clear understanding of the pathogenesis of all observed changes and a lack of a uniform definition for the HIV associated metabolic syndrome exists. Researchers initially believed that this "new" HIV metabolic syndrome shares basic pathophysiologic principles with metabolic changes seen in healthy populations as they get older ${ }^{[9]}$. Attempts to use a common definition for "lipodystrophy" have been made ${ }^{[16-20]}$ but are not yet widely accepted.

Adipokines and their physiologic role: Adipose tissue with both its adipocyte and non adipocyte fractions represents a major endocrine organ secreting hormones and other proteins including inflammatory mediators such as plasminogen activator inhibitor type 1 , TNF- $\alpha$, IL-6 and hormones involved in insulin sensitivity like leptin and adiponectin ${ }^{[21-27]}$. All adipose tissue products seem to contribute significantly in various metabolic processes both at the local and the systemic level ${ }^{[21]}$. Additionally adipocytes express numerous receptors enabling them to respond to distant signals from other hormonal systems ${ }^{[21]}$. These include insulin and androgen receptors. A recent review describes at least

Corresponding Author: Christos S. Mantzoros, M.D., D.Sc., Division of Endocrinology, Diabetes and Metabolism Beth Israel Deaconess Medical Center, Harvard Medical School, 330 Brookline Avenue, ST 816, Boston, Massachusetts, 02215, U.S.A. Tel: 6176678630, Fax: 6176678634 
19 different secreted proteins and at least 22 receptors expressed in adipose tissue ${ }^{[21]}$. The metabolic syndrome in non HIV patients is characterized by hyperinsulinemia, type 2 diabetes mellitus, hypertension, hyperlipidemia and coronary heart disease and the adipose tissue seems to play an important role in its pathogenesis ${ }^{[21,28-30]}$.

Leptin and its physiologic role: Leptin is an adipocyte derived hormone involved in energy homeostasis and insulin resistance via central effects on the hypothalamus and peripheral effects on fatty acid oxidation $^{[22,31,32]}$. In humans, hypothalamic pathways mediate the leptin effects in energy homeostasis and leptin seems to primarily serve as a signal of sufficient energy for the human body ${ }^{[22]}$. If an individual starts to receive less nutrition and loses weight, leptin levels will decrease and concomitantly through a mechanism of physiologic adaptation appetite will be increased and energy expenditure will decline $e^{[22,33-35]}$. In mice experiments leptin deficiency has been associated with hyperinsulinemia and insulin resistance that is corrected by exogenous administration of leptin before the development of persistent obesity ${ }^{[36,37]}$. However only a few humans are similar to these ob/ob mice; high instead of low leptin levels most often accompany obesity representing likely a state of leptin resistance $^{[22,33,38]}$. Studies in HIV-1 negative individuals have shown an association berween higher fasting leptin levels and obesity, total and central fat accumulation as well as insulin resistance ${ }^{[39,40]}$. Leptin levels directly correlate to adipose tissue mass (subcutaneous rather than visceral adipose tissue) as well as nutritional status in humans ${ }^{[41-43]}$. It has been recently shown by researchers in our group that increasing fat mass is associated with higher baseline leptin levels and endogenous production rates ${ }^{[44]}$. In the same work leptin clearance was decreasing with increased adiposity leading to higher leptin levels in obese subjects and a state of leptin resistance ${ }^{[44]}$. Leptin is an adipose tissue product and thus low fat stores could result in hypoleptinemia in any patient with lipoatrophy. A generalized loss of subcutaneous and visceral fat, insulin resistance and hyperlipidemia is characteristic of the rare congenital and acquired lipoatrophies seen in humans ${ }^{[45-47]}$. Leptin replacement in subjects with such syndromes has improved glycemic control and lipid levels in a recently published interventional human study ${ }^{[48]}$.

Leptin besides its effects on energy homeostasis has regulatory effects on other traditional endocrine systems such as the hypothalamic-pituitary-gonadal axis and in part, the hypothalamic-pituitary-thyroid axis especially in starvation-states ${ }^{[49,50]}$. In leptin deficiency states there is suppression of the thyroid and the gonadal axis which is reversed with leptin supplementation $^{[49-52]}$. In addition leptin may have a regulatory role for the hypothalamic-pituitary-adrenal axis (HPA). In leptin deficiency states there is an activation of the HPA axis with increased levels of corticotrophin-releasing hormone (CRH) and hypercortisolemia an effect shown in mice experiments and in vitro experiments involving human adrenocortical cells ${ }^{[21]}$.

Leptin and the HIV associated metabolic syndrome: Fasting leptin levels have been shown to correlate well with total body fat concentrations in HIV-infected patients ${ }^{[53-55]}$. An association between limb fat loss and low leptin levels as well as other metabolic abnormalities in HIV patients has been published ${ }^{[56]}$ however other studies failed to show such associations likely due to lack of stratification of patients by type of lipodystrophic body changes ${ }^{[57,58]}$. After careful categorization of HIV-1 infected patients attending our ID clinic in 4 separate body habitus categories (lipohypertrophy, lipoatrophy, mixed, normal) ${ }^{[59]}$, we hypothesized that we will observe leptin deficiency resulting from decreased synthesis and/or release of leptin from adipocytes in patients exhibiting either peripheral or generalized lipoatrophy ${ }^{[59]}$. We found a significant association between leptin levels and insulin resistance in patients with the various morphological phenotypes ${ }^{[59]}$. Mean leptin levels were lowest in patients exhibiting lipoatrophic body shape changes when compared to those of patients with lipohypertrophy who had the highest leptin levels ${ }^{[59]}$. Leptin levels in between the two extremes were observed in subjects with no body shape changes ${ }^{[59]}$. Hypoleptinemia was independently associated with insulin resistance in patients with lipoatrophy an effect not confounded by central or peripheral fat mass indicating a possible role for leptin in the development of metabolic changes in lipoatrophic patients ${ }^{[59]}$. This finding generated the hypothesis that leptin administration in leptin deficient HIV positive subjects with lipoatrophy would result in correction of the metabolic disturbance i.e. insulin resistance, as a proof of concept for its role in causing the syndrome ${ }^{[59]}$. Another interesting finding of our study was the hyperleptinemia noted in HIV patients with hypertrophy ${ }^{[59]}$. This could be attributed to excess synthesis and release of leptin by the adipocytes or excess circulating levels of free unbound leptin due to resistance at the leptin receptor level ${ }^{[59]}$.

Recently a significant association between leptin secretion and subcutaneous fat has been reported in studies of leptin pulse dynamics in relation to the morphologic changes in HIV patients ${ }^{[60]}$. The researchers reported a decrease in leptin levels following subcutaneous fat decrements after controlling for visceral fat quantity ${ }^{[60]}$. There was no specific relationship discovered with visceral fat however this study did not study purely lipoatrophic patients ${ }^{[60]}$. Of note in the study by our group lipoatrophic subjects had the highest percentage of visceral fat ${ }^{[59]}$. Future research 
is necessary to investigate the role of regional fat changes in producing hypoleptinemia ${ }^{[60]}$. Leptin gene expression and leptin production from regional fat compartments could be decreased due to fat loss ${ }^{[61]}$. Leptin effects may be fat type specific. Adipose tissue lacking leptin is unable to correct the metabolic abnormalities associated with lipoatrophy when transplanted $^{[62]}$ to mice as opposed to adipose tissue producing leptin i.e. subcutaneous fat ${ }^{[63]}$. Leptin exerts several other important actions ${ }^{[64,65]}$ that need to be further explored in HIV subjects.

Adiponectin and its physiological role: Adiponectin is a newly appreciated hormone discovered 10 years ago and exclusively produced from mature adipocytes ${ }^{[66-69]}$. Adiponectin has a collagen like and a globular like domain and has tertiary structural similarities with an important inflammatory cytokine, tumor necrosis factor alpha $(\mathrm{TNFa})^{[66-70]}$. Adiponectin has been found to be inversely associated with components of the metabolic syndrome such as obesity, insulin resistance and type II diabetes ${ }^{[71-74]}$, as well as rare forms of congenital and acquired lipodystrophies in non-HIV infected patients ${ }^{[75]}$. Adiponectin effects not only depend on the circulating concentrations of the hormone but also on the expression of recently identified specific receptors at the muscle (adipoR1) and/or the liver (adipoR2) ${ }^{[76]}$. Adiponectin has a beneficial effect on insulin resistance which can be explained by two main mechanisms. First, adiponectin mediates an overall decrease of triglycerides in muscle and liver by up-regulating the expression of molecules involved in fatty acid oxidation and muscle energy expenditure. This has been demonstrated in experiments involving obese mice [77]. Second, adiponectin inhibits gluconeogenesis at the liver ${ }^{[78,79]}$. Decreased levels of both leptin and adiponectin have been seen in animal models of lipoatrophy where transgenic overexpression or administration of one of the two partially corrected insulin resistance while administration of both hormones resulted in complete reversal of the insulin resistance state ${ }^{[80,81]}$. Recent studies have shown that adiponectin expression is higher in subcutaneous than visceral fat in humans ${ }^{[41]}$.

Adiponectin and the HIV associated metabolic syndrome: In further studies of HIV patients with "lipodystrophy" followed at our institution we found that adiponectin levels were significantly lower in the patients exhibiting fat redistribution changes ${ }^{[82]}$. This association was independent of age, leptin levels, HIV medication and severity of disease ${ }^{[82]}$. Adiponectin levels were significantly associated with both abdominal visceral fat and extremity fat ${ }^{[82]}$. Since adiponectin expression is higher in subcutaneous than visceral fat in humans ${ }^{[41]}$ visceral fat accumulation and subcutaneous fat loss may lead to decreased adiponectin production both in lipoatrophy and lipohypertrophy subjects. This adiponectin deficiency becomes more prominent with peripheral fat loss and thus loss of another adiponectin supply. Thus, fat redistribution may actually be responsible for the decreased adiponectin levels in HIV patients with mixed fat redistribution phenotypes ${ }^{[82]}$. Further confirming this hypothesis we found an inverse relation between adiponectin levels and abdominal visceral fat mass, serum triglycerides and insulin resistance ${ }^{[82]}$. These findings are consistent with the role of visceral adiposity in the development of insulin resistance and lipid abnormalities associated with the metabolic syndrome ${ }^{[83-86]}$. Subsequent studies confirmed our results showing an association between adiponectin levels and insulin sensitivity in HIV positive subjects ${ }^{[55,87,88]}$. Reduced circulating adiponectin levels were reported in patients with chronic HIV infection and fat redistribution compared with age- and body mass index-matched HIV-infected patients without fat redistribution ${ }^{[87]}$. Adiponectin concentrations correlated with body composition, insulin response to glucose challenge and lipid levels ${ }^{[87]}$. Thus adiponectin may be a better marker than leptin for insulin resistance seen in HIV subjects ${ }^{[89]}$. Taking these findings to the molecular level researchers have recently shown decreased adiponectin specific mRNA levels in fat biopsies from such lipodystrophic patients ${ }^{[90]}$.

All the above results support the hypothesis that correction of adiponectin levels may ameliorate the metabolic changes observed in HIV patients.

Uncertainty exists with regards to medication effects on adiponectin levels and is compounded by their effects on adipogenesis and/or fat loss. Our study showed that certain HIV medications (NRTIs) may mediate part of hypoadiponectinemia (eg through peripheral lipoatrophy) ${ }^{[82]}$. A recent sudy reported an association of peripheral lipoatrophy and low levels of adiponectin in patients currently or previously treated with stavudine ${ }^{[91]}$. Among PIs ritonavir has be shown to adversely affect adiponectin as well as lipid levels in animal experiments ${ }^{[86,92]}$. The administration of adiponectin improved these changes ${ }^{[86,92]}$. It is likely that decreased adiponectin levels are mediated by PI effects on adipogenesis. Indeed in vitro experiments have shown that protease inhibitors inhibit adipogenesis in a dose response manner in murine 3T3-L1 preadipocytes $^{[93]}$. However the effects of individual protease inhibitors on adipogenesis and adiponectin levels may vary from PI to PI similarly to their effects on insulin resistance (see above) and may vary from animal to human experiments. In a recent effort adipokine levels were measured in HIV-negative men treated with either indinavir or lopinavir/ritonavir ${ }^{[94]}$. Serum adiponectin levels increased with both agents despite their differential effects on insulin sensitivity ${ }^{[94]}$ and in contrast with the above mentioned in vitro experiments that have showed decreased adiponectin expression in 3T3 adipocytes acutely treated with 
several PIs and NRTIs ${ }^{[93]}$. Of note adiponectin levels increased after a few weeks of therapy suggesting a compensatory response from the adipose tissue through a negative feedback mechanism at least at the initial stages of the metabolic dysregulation. Studies examining these effects at the human fat cell level have looked at regional adipose cells obtained from HIV negative individuals treated with PIs and nucleoside analogues. In these experiments both PIs and NRTIs downregulated adiponectin expression from subcutaneous adipose tissue cells ${ }^{[95]}$. Thus it seems that during early phases of antiretroviral therapy adiponectin expression is likely downregulated by direct medication effects. Later on changes of adipose tissue may lead to hypoadiponectinemia at later stages of the metabolic syndrome. Interestingly in some studies there is an inverse relationship between adiponectin and TNF$a^{[95,96]}$ raising the hypothesis that increased levels of TNF-a -another adipocytokine itself- may contribute to the pathogenesis of lipodystrophy ${ }^{[95,96]}$. Ritonavir use in human adipocyte cell lines was able both to up-regulate TNF-a, IL6 and leptin expression and down-regulate PPAR- $\gamma$ and adiponectin expression ${ }^{[96]}$ in one of these studies. It is well known that in HIV negative subjects TNF- $\alpha$ suppresses the expression of transcriptional factors involved in adipogenesis and lipogenesis including a downregulation of adiponectin and IL$6^{[21,97]}$. Increased TNF- $\alpha$ from abdominal subcutaneous adipose tissue as well as elevated circulating levels of IL-6, soluble TNF receptors I and II and insulin have been observed in HIV patients with fat redistribution ${ }^{[98-}$ 101]. Moroever decreased adiponectin and leptin expression resulting form increased apoptosis together with decreased adipocyte differentiation has been found in experiments looking at adipose tissue from HIV subjects with peripheral lipoatrophy when compared with samples from HIV negative controls ${ }^{[102]}$ further confirming previous similar observations ${ }^{[103]}$. These leptin and adiponectin changes likely mediated the insulin resistance found in these subjects ${ }^{[102]}$. The observed adipocyte changes were partly explained by increased levels of TNF-a and interleukin-6 (IL-6) ${ }^{[102]}$. Obviously it would be interesting to see whether such associations are observed in HIV patients examined both at early and later stages of antiretroviral therapy ${ }^{[94]}$.

Thus one can formulate the hypothesis that HIV positive patients suffering from the HIV associated metabolic syndrome suffer from a pre-inflammatory state similar to the one seen in the metabolic syndrome affecting a large fraction of the general population in developed countries ${ }^{[104,105]}$. These inflammatory changes affect adiponectin and/or leptin production. Recent work performed in our lab has confirmed an association of adiponectin and inflammatory markers such as CRP likely mediated through an underlying association with obesity in diabetic subjects ${ }^{[106]}$. The role of inflammatory cytokines in the pathogenesis of
HIV lipodystrophy is of great interest but is outside the scope of the current review.

Effects on sterol-regulatory-element-bindingprotein-1c (SREBP-1c) a transcription factor involved in the activation of genes responsible for long chain fatty acid synthesis and adipocyte differentiation ${ }^{[107-109]}$ seem to be important in the pathogenesis of the HIV metabolic syndrome especially dyslipidemia and body shape changes. Experiments with transgenic mice overexpressing SREBP-1c exhibit a metabolic syndrome similar to the one seen in HAART treated patients with lipoatrophy, insulin resistance and hypertriglyceridemia ${ }^{[110]}$. Increased SREBP-1c concentration in peripheral adipose tissue has been recently associated with decreased expression of PPAR$\gamma$ and decreased adipocyte differentiation in HIV patients who developed lipoatrophy after receiving HAART-therapy ${ }^{[111]}$. Decreased levels of leptin were noted in these patients together with increased TNF- $\alpha$ suggesting impaired adipocyte differentiation and thus decreased adiponectin levels ${ }^{[111]}$ although adiponectin levels were not specifically measured.

Decreased adipocyte differentiation or loss, leading to a decrease in adiponectin, concomitantly with increased secretion of other inflammatory cytokines (e.g. TNF-a) may in part explain the insulin resistance in HIV positive subjects. Some of these effects maybe the result of synergistic actions by different key etiopathogenetic factors. For example, protease inhibitors may synergistically act with TNF- $\alpha$ in producing antiadipogenic effects ${ }^{[112]}$.

These complex interactions may actually be the result of a fine balance between effects of several specific antiretrovirals, age, as well as the effect of the HIV illness itself, other concomitant illnesses and/or genetic predisposition ${ }^{[113]}$. Furthermore, they may change and evolve depending on other factors such as age and environmental stimuli e.g. diet and exercise.

Therapeutic implications of the adipokine role: Several strategies have been incorporated in clinical practice in an attempt to handle the several manifestations of the HIV metabolic syndrome $e^{[1,114-118]}$. We will briefly discuss thiazolidinedione effects and their association with adipocytokine changes as well as therapy for lipoatrophy with leptin.

Thiazolidinediones and their effects on the HIV associated metabolic syndrome: Thiazolidinedione are PPAR- $\gamma$ agonists that initiate a cascade of events leading to transcription or inhibition of genes involved in the regulation of adipocyte differentiation, lipid metabolism and insulin action ${ }^{[119-121]}$. It is well known from in vitro experiments that PPAR- $\gamma$ agonists increase adiponectin expression in the adipose tissue ${ }^{[120]}$ and treatment with thiazolidinediones in vivo markedly increases circulating adiponectin levels ${ }^{[122,123]}$. 
One of the first theories to be presented to explain the lipodystrophy syndrome was that antiretroviral medications directly decrease adipocyte differentiation by inhibiting the activation of nuclear receptors involved in adipocyte differentiation and insulin induced metabolic changes ${ }^{[124,125]}$. This hypothesis has been questioned in subsequent studies ${ }^{[126-128]}$. If part of the theory is correct ${ }^{[128]}$ we would expect to see some beneficial effects of PPAR- $\gamma$ therapy in HIV associated metabolic changes. Moreover the physiologic associations observed in the studies discussed previously would rationalize thiazolidinendione treatment for some of these changes.

Indeed rosiglitazone has been shown to improve insulin resistance in patients with HIV associated metabolic syndrome, however at the expense of increased triglyceride and cholesterol concentrations ${ }^{[129-}$ 132]. Regarding fat redistribution the initially encouraging results reporting a beneficial effect of rosiglitazone in body fat gain ${ }^{[129,130]}$ were not seen during two other studies including a recent larger $(n=108)$ placebo controlled study ${ }^{[131]}$ evaluating rosiglitazone in lipoatrophic HIV patients ${ }^{[131,132]}$. This has led to the speculation that rosiglitazone may exert its insulin sensitizing effects without increasing the subcutaneous adipose tissue mass ${ }^{[132]}$. Of note a significant increase in baseline PPAR $-\gamma$ expression in adipose tissue is noted with rosiglitazone in HIV positive subjects ${ }^{[133]}$. Thiazolidinediones may act through other mechanisms as well. A recent study examined gene expression in subcutaneous tissue from subjects with lipodystrophy and showed significantly higher levels of 11-beta hydroxysteroid dehydrogenase type-1 in lipodystrophic HIV subjects compared to non lipodystrophy cases ${ }^{[134]}$. In the liver and adipose tissue 11 beta hydroxysteroid dehydrogenase type 1 catalyzes a cortisol forming reaction and transgenic mice overexpressing this enzyme develop a full blown metabolic syndrome with obesity and increased amounts of visceral fat ${ }^{[135]}$. Thiazolidinediones downregulate 11-beta hydroxysteroid dehydrogenase type 1 enzyme in adipose tissue and their effect could be partially explained by this mechanism ${ }^{[136]}$. This effect is probably not mediated by the action of protease inhibitors since previous experiments using adipose stromal cells have shown a dose dependent inhibition of this enzyme by saquinavir, indinavir and nelfinavir ${ }^{[137]}$.

Pioglitazone is another thiazolidinedione which has a more favorable effect on lipid profile compared to rosiglitazone ${ }^{[138,139]}$. In a recently performed open label uncontrolled study its use in HIV patients was associated with adverse effects on insulin resistance and an increase in fat mass with no adverse lipid effects ${ }^{[140]}$. Our group looked at the effects of pioglitazone and/or fenofibrate (a PPAR- $\alpha$ agonist) in a group of HIV infected patients suffering from insulin resistance or diabetes and/or hyperlipidemia in a randomized controlled study ${ }^{[141]}$. Pioglitazone administration over
12 months improved insulin resistance and blood pressure and affected the lipid profile favorably by increasing HDL levels in these patients ${ }^{[141]}$. With regards to fat redistribution effects we observed a trend towards an increase of total body and abdominal fat over the 12 month pioglitazone use by our HIV subjects $^{[141]}$. A significant increase in adiponectin levels over the study period which was not found in the placebo group might have mediated the beneficial effect in insulin resistance in our patients ${ }^{[141]}$. These effects could be attributed to increased adiponectin gene expression which has been reported in association with rosiglitazone therapy recently ${ }^{[133]}$. Adiponectin and PPAR- $\gamma$ expression in adipose tissue has been reported to be significantly lower in HIV-infected patients with HAART-induced fat redistribution ${ }^{[103]}$. Other mechanisms could be potentially involved, such as a decrease in free fatty acid levels, however pioglitazone did not significantly affect their concentration in our study $^{[141]}$. Pioglitazone based on its beneficial lipid effects seems a better thiazolidinedione for the treatment of diabetes in HIV-infected subjects. Another thiazolidinedione which exhibited similar effects, troglitazone, had to be withdrawn from the market due to unacceptable liver toxicity ${ }^{[142]}$.

In conclusion, pioglitazone in preliminary studies appears to have a beneficial effect on insulin resistance mediated by adiponectin levels and favorably affects the lipid profile in the HIV associated metabolic syndrome. Larger studies are necessary to elucidate the role of PPAR $\gamma$ agonsists alone or in combination with other agents i.e. PPAR $\alpha$ agonists or recombinant leptin in treating HIV related fat redistribution and especially lipoatrophy and/or insulin resistance.

In using thiazolidinediones one should keep in mind potential antiretroviral effects of this class of medications $^{[143]}$ which are probably mediated by downregulation of TNF- $\alpha$ and IL- $6^{[144]}$ which are known to promote HIV transcription ${ }^{[144]}$. More importantly during thiazolidinedione therapy careful monitoring for important associated side effects like liver toxicity is essential ${ }^{[119]}$.

Leptin therapy and the HIV associated metabolic syndrome: Recently, leptin administration was used to treat congenital and acquired (non-HIV) lipodystrophy ${ }^{[48]}$. It took four months to achieve physiological leptin concentrations in these patients ${ }^{[48]}$. Leptin administration resulted in improvement of hyperglycemia, hyperinsulinemia, hypertriglyceridemia, as well as a significant decrease in fatty infiltration of the liver ${ }^{[48]}$. In light of the previous discussion and the observed leptin deficiency in patients with HIV/HAART-associated lipoatrophy ${ }^{[59]}$, leptin administration alone or in combination with thiazolidinediones or switch strategies could in theory reverse many of the metabolic abnormalities observed in this syndrome. Studies are 
currently under way and preliminary results are encouraging for HIV patients with lipoatrophy and low leptin levels ${ }^{[145]}$. Leptin replacement therapy induced improvements in insulin resistance after 2 months of therapy in HIV (+) lipoatrophic leptin deficient subjects $^{[145]}$.

\section{CONCLUSION}

Multiple mechanistic pathways may overlap in producing several manifestations of the HIV associated metabolic syndrome. Further research may be able to elucidate the three-fold association between acute antiretroviral treatment effects and adiponectin and/or leptin levels as well as insulin resistance. These changes should be studied both at early and late treatment stages, in various regional adipose tissue compartments and in the circulation. The predictive value of such changes for the subsequent development of fat redistribution or other metabolic changes should be estimated and the effect of medications that normalize leptin and adiponectin levels should be studied. This will further enhance our understanding of the complex associations and interrelations between a chronic infection, toxic drugs, genetic predisposition and environmental factors participating in generating the HIV metabolic syndrome.

\section{REFERENCES}

1. Leow, M.K., C.L. Addy and C.s. Mantzoros, 2003. Clinical review 159: Human immunodeficiency virus/highly active antiretroviral therapy-associated metabolic syndrome: clinical presentation, pathophysiology and therapeutic strategies. J. Clin. Endocrinol. Metab., 88: 1961-76.

2. Friis-Moller, N., R. Weber and P. Reiss et al., 2003. Cardiovascular disease risk factors in HIV patients--association with antiretroviral therapy. Results from the DAD study. AIDS, 17: 117993.

3. Friis-Moller, N., C.A. Sabin and R. Weber et al., 2003. Combination antiretroviral therapy and the risk of myocardial infarction. N. Engl. J. Med., 349: 1993-2003.

4. Kino, T. and G.P. Chrousos, 2004. Human immunodeficiency virus type-1 accessory protein Vpr: a causative agent of the AIDS-related insulin resistance/lipodystrophy syndrome? Ann. N.Y. Acad. Sci., 1024: 153-67.

5. Grunfeld, C. and P. Tien, 2003. Difficulties in understanding the metabolic complications of acquired immune deficiency syndrome. Clin. Infect. Dis., 37 (Suppl. 2): S43-6.

6. Behrens, G., A. Dejam and H. Schmidt et al., 1999. Impaired glucose tolerance, beta cell function and lipid metabolism in HIV patients under treatment with protease inhibitors. AIDS, 13: F63-70.
7. Carr, A., K. Samaras and S. Burton et al., 1998. A syndrome of peripheral lipodystrophy, hyperlipidaemia and insulin resistance in patients receiving HIV protease inhibitors. AIDS, 12: F51-8.

8. Carr, A., K. Samaras, A. Thorisdottir, G.R. Kaufmann, D.J. Chisholm and D.A Cooper, 1999. Diagnosis, prediction and natural course of HIV-1 protease-inhibitor-associated lipodystrophy, hyperlipidaemia and diabetes mellitus: A cohort study. Lancet, 353: 2093-9.

9. Tsiodras, S., C. Mantzoros, S. Hammer and M. Samore, 2000. Effects of protease inhibitors on hyperglycemia, hyperlipidemia and lipodystrophy: A 5-year cohort study. Arch. Intern. Med., 160: 2050-6.

10. Vigouroux, C., S. Gharakhanian and Y. Salhi et al., 1999. Adverse metabolic disorders during highly active antiretroviral treatments (HAART) of HIV disease. Diabetes Metab., 25: 383-92.

11. Struble, K. and S.C. Piscitelli, 1999. Syndromes of abnormal fat redistribution and metabolic complications in HIV-infected patients. Am. J. Health. Syst. Pharm., 56: 2343-8.

12. Miller, K.K., P.A. Daly and D. Sentochnik et al., 1998. Pseudo-Cushing's syndrome in human immunodeficiency virus-infected patients. Clin. Infect. Dis., 27: 68-72.

13. Stocker, D.N., P.J. Meier, R. Stoller and K.E. Fattinger, 1998. Buffalo hump in HIV-1 infection. Lancet, 352: 320-1.

14. Engelson, E.S., D.P. Kotler and T. Tan et al., 1999. Fat distribution in HIV-infected patients reporting truncal enlargement quantified by whole-body magnetic resonance imaging. Am. J. Clin. Nutr., 69: 1162-9.

15. Hadigan, C., J.B. Meigs and C .Corcoran et al., 2001. Metabolic abnormalities and cardiovascular disease risk factors in adults with human immunodeficiency virus infection and lipodystrophy. Clin. Infect. Dis., 32: 130-9.

16. Carter, V.M., J.F. Hoy, M. Bailey, P.G. Colman, I. Nyulasi and A.M. Mijch, 2001. The prevalence of lipodystrophy in an ambulant HIV-infected population: it all depends on the definition. HIV Med., 2: 174-80.

17. Ioannidis, J.P., T.A. Trikalinos, M. Law and A. Carr, 2003. HIV lipodystrophy case definition using artificial neural network modelling. Antivir. Ther., 8: 435-41.

18. Moyle, G., 2002. Lipodystrophy: Lack of agreement on definition and etiology presents a challenge to research and therapy. AIDS Read, 12: 438, 440-2. 
19. Carr, A. and M. Law, 2003. An objective lipodystrophy severity grading scale derived from the lipodystrophy case definition score. J. Acquir. Immune. Defic. Syndr., 33: 571-6.

20. Carr, A., S. Emery, M. Law, R. Puls, J.D. Lundgren and W.G. Powderly, 2003. An objective case definition of lipodystrophy in HIV-infected adults: a case-control study. Lancet, 361: 726-35.

21. Kershaw, E.E. and J.S. Flier, 2004. Adipose tissue as an endocrine organ. J. Clin. Endocrinol. Metab., 89: 2548-56.

22. Mantzoros, C.S., 1999. The role of leptin in human obesity and disease: a review of current evidence. Ann. Intern. Med., 130: 671-80.

23. Shimomura, I., T. Funahashi and M. Takahashi et al., 1996. Enhanced expression of PAI-1 in visceral fat: possible contributor to vascular disease in obesity. Nat. Med., 2: 800-3.

24. Alessi, M.C., F. Peiretti, P. Morange, M. Henry, G. Nalbone and I. Juhan-Vague, 1997. Production of plasminogen activator inhibitor 1 by human adipose tissue: possible link between visceral fat accumulation and vascular disease. Diabetes, 46: 860-7.

25. Hotamisligil, G.S. and B.M. Spiegelman, 1994. Tumor necrosis factor alpha: a key component of the obesity-diabetes link. Diabetes, 43: 1271-8.

26. Hotamisligil, G.S., D.L. Murray, L.N. Choy and B.M. Spiegelman, 1994. Tumor necrosis factor alpha inhibits signaling from the insulin receptor. Proc. Natl. Acad. Sci. USA, 91: 4854-8.

27. Hanson, K. and R. Pratley, 2000. Interleukin-6 is associated with insulin resistance independently of obesity (abstract). Diabetes, 49 (Suppl. 1): A297.

28. Dunbar, R.L. and D.J. Rader, 2004. Slaying the metabolic syndrome. Are we battling the Hydra or the Chimera? Minerva Endocrinol., 29: 89111.

29. Matsuzawa, Y., T. Funahashi and T. Nakamura, 1999. Molecular mechanism of metabolic syndrome $\mathrm{X}$ : contribution of adipocytokines adipocyte-derived bioactive substances. Ann. N.Y. Acad. Sci., 892: 146-54.

30. Reitman, M.L., E. Arioglu, O. Gavrilova and S.I. Taylor, 2000. Lipoatrophy revisited. Trends Endocrinol. Metab., 11: 410-6.

31. Halaas, J.L., K.S. Gajiwala and M. Maffei et al., 1995. Weight-reducing effects of the plasma protein encoded by the obese gene. Science, 269: 543-6.

32. Zhang, Y., R. Proenca, M. Maffei, M. Barone, L. Leopold and J.M. Friedman, 1994. Positional cloning of the mouse obese gene and its human homologue. Nature, 372: 425-32.
33. Bjorbaek, C. and B.B. Kahn, 2004. Leptin signaling in the central nervous system and the periphery. Recent Prog. Horm. Res., 59: 305-31.

34. Flier, J.S., 1998. Clinical review 94: What's in a name? In search of leptin's physiologic role. J. Clin. Endocrinol. Metab., 83: 1407-13.

35. Friedman, J.M. and J.L. Halaas, 1998. Leptin and the regulation of body weight in mammals. Nature, 395: 763-70.

36. Shimomura, I., R.E. Hammer, S. Ikemoto, M.S. Brown and J.L. Goldstein, 1999. Leptin reverses insulin resistance and diabetes mellitus in mice with congenital lipodystrophy. Nature, 401: 736.

37. Ebihara, K., Y. Ogawa and H. Masuzaki et al., 2001. Transgenic overexpression of leptin rescues insulin resistance and diabetes in a mouse model of lipoatrophic diabetes. Diabetes, 50: 1440-8.

38. Flier, J.S., 2004. Obesity wars: molecular progress confronts an expanding epidemic. Cell, 116: 337-50.

39. Considine, R.V., M.K. Sinha and M.L. Heiman et al., 1996. Serum immunoreactive-leptin concentrations in normal-weight and obese humans. N. Engl. J. Med., 334: 292-5.

40. Maffei, M., J. Halaas and E. Ravussin et al., 1995. Leptin levels in human and rodent: measurement of plasma leptin and ob RNA in obese and weight-reduced subjects. Nat. Med., 1: 1155-61.

41. Fain, J.N., A.K. Madan, M.L. Hiler, P. Cheema and S.W. Bahouth, 2004. Comparison of the release of adipokines by adipose tissue, adipose tissue matrix and adipocytes from visceral and subcutaneous abdominal adipose tissues of obese humans. Endocrinology, 145: 2273-82.

42. Wajchenberg, B.L., 2000. Subcutaneous and visceral adipose tissue: their relation to the metabolic syndrome. Endocr. Rev., 21: 697-738.

43. Wajchenberg, B.L., D. Giannella-Neto, M.E. da Silva and R.F. Santos, 2002. Depot-specific hormonal characteristics of subcutaneous and visceral adipose tissue and their relation to the metabolic syndrome. Horm. Metab. Res., 34: 616-21.

44. Wong, S.L., A.M. DePaoli, J.H. Lee and C.S. Mantzoros, 2004. Leptin hormonal kinetics in the fed state: effects of adiposity, age and gender on endogenous leptin production and clearance rates. J. Clin. Endocrinol. Metab., 89: 2672-7.

45. Flier, J. and C. Mantzoros, 2001. Syndromes of Insulin Resistance and Mutant Insulin. DeGroot L., Ed. Endocrinology. 4th Edn. New York: Saunders, pp: 799-809. 
46. Garg, A., Lipodystrophies. Am. J. Med., 108: 143-52.

47. Garg, A., Acquired and inherited lipodystrophies. N. Engl. J. Med., 350: 1220-34.

48. Oral, E.A., V. Simha and E. Ruiz et al., 2002. Leptin-replacement therapy for lipodystrophy. N. Engl. J. Med., 346: 570-8.

49. Chan, J.L., K. Heist, A.M. DePaoli, J.D. Veldhuis and C.S. Mantzoros, 2003. The role of falling leptin levels in the neuroendocrine and metabolic adaptation to short-term starvation in healthy men. J. Clin. Invest., 111: 1409-21.

50. Welt, C.K., J.L. Chan and J. Bullen et al., 2004. Recombinant human leptin in women with hypothalamic amenorrhea. N. Engl. J. Med., 351: 987-97.

51. Flier, J.S., M. Harris and A.N. Hollenberg, 2000. Leptin, nutrition and the thyroid: the why, the wherefore and the wiring. J. Clin. Invest., 105: 859-61.

52. Hileman, S.M., D.D. Pierroz and J.S. Flier, 2000. Leptin, nutrition and reproduction: timing is everything. J. Clin. Endocrinol. Metab., 85: 8047.

53. Yarasheski, K.E., J.J. Zachwieja, M.M. Horgan, W.G. Powderly, J.V. Santiago and M. Landt, 1997. Serum leptin concentrations in human immunodeficiency virus-infected men with low adiposity. Metabolism, 46: 303-5.

54. Mynarcik, D.C., T. Combs, M.A. McNurlan, P.E. Scherer, E. Komaroff and M.C. Gelato, 2002. Adiponectin and leptin levels in HIVinfected subjects with insulin resistance and body fat redistribution. J. Acquir. Immune. Defic. Syndr., 31: 514-20.

55. Kosmiski, L., D. Kuritzkes, K. Lichtenstein and R. Eckel, 2003. Adipocyte-derived hormone levels in HIV lipodystrophy. Antivir. Ther., 8: 9-15.

56. Estrada, V., M. Serrano-Rios and M.T. Martinez Larrad et al., 2002. Leptin and adipose tissue maldistribution in HIV-infected male patients with predominant fat loss treated with antiretroviral therapy. J. Acquir. Immune. Defic. Syndr., 29: 32-40.

57. Christeff, N., J.C. Melchior, P. de Truchis, C. Perronne, E.A. Nunez and M.L. Gougeon, 1999. Lipodystrophy defined by a clinical score in HIV-infected men on highly active antiretroviral therapy: Correlation between dyslipidaemia and steroid hormone alterations. AIDS, 13: 2251-60.

58. Vigouroux, C., S. Gharakhanian and Y. Salhi et al., 1999. Diabetes, insulin resistance and dyslipidaemia in lipodystrophic HIV-infected patients on highly active antiretroviral therapy (HAART). Diabetes Metab., 25: 225-32.

59. Nagy, G.S., S. Tsiodras and L.D. Martin et al., 2003. Human immunodeficiency virus type 1related lipoatrophy and lipohypertrophy are associated with serum concentrations of leptin. Clin. Infect. Dis., 36: 795-802.
60. Koutkia, P., B. Canavan, J. Breu, M.L. Johnson, A. Depaoli and S.K. Grinspoon, 2004. Relation of leptin pulse dynamics to fat distribution in HIV-infected patients. Am. J. Clin. Nutr., 79: 1103-9.

61. Van Harmelen, V., S. Reynisdottir and P. Eriksson et al., 1998. Leptin secretion from subcutaneous and visceral adipose tissue in women. Diabetes, 47: 913-7.

62. Colombo, C., J.J. Cutson and T. Yamauchi et al., 2002. Transplantation of adipose tissue lacking leptin is unable to reverse the metabolic abnormalities associated with lipoatrophy. Diabetes, 51: 2727-33.

63. Gavrilova, O., B. Marcus-Samuels and D. Graham et al., 2000. Surgical implantation of adipose tissue reverses diabetes in lipoatrophic mice. J. Clin. Invest., 105: 271-8.

64. Lord, G.M., G. Matarese, J.K. Howard, R.J. Baker, S.R. Bloom and R.I. Lechler, 1998. Leptin modulates the $\mathrm{T}$-cell immune response and reverses starvation-induced immunosuppression. Nature, 394: 897-901.

65. Gougeon, M.L., L. Penicaud, B. Fromenty, P. Leclercq, J.P. Viard and J. Capeau, 2004. Adipocytes targets and actors in the pathogenesis of HIV-associated lipodystrophy and metabolic alterations. Antivir. Ther., 9: 161-77.

66. Maeda, K., K. Okubo, I. Shimomura, T. Funahashi, Y. Matsuzawa and K. Matsubara, 1996. cDNA cloning and expression of a novel adipose specific collagen-like factor, apM1 (AdiPose Most abundant Gene transcript 1). Biochem. Biophys. Res. Commun., 221: 286-9.

67. $\mathrm{Hu}$ E, P. Liang and B.M. Spiegelman, 1996. AdipoQ is a novel adipose-specific gene dysregulated in obesity. J. Biol. Chem., 271: 10697-703.

68. Nakano, Y., T. Tobe, N.H. Choi-Miura, T. Mazda and M. Tomita, 1996. Isolation and characterization of GBP28, a novel gelatinbinding protein purified from human plasma. $\mathbf{J}$. Biochem. (Tokyo), 120: 803-12.

69. Scherer, P.E., S. Williams, M. Fogliano, G. Baldini and H.F. Lodish, 1995. A novel serum protein similar to $\mathrm{C} 1 \mathrm{q}$, produced exclusively in adipocytes. J. Biol. Chem., 270: 26746-9.

70. Chandran, M., S.A. Phillips, T. Ciaraldi and R.R. Henry, 2003. Adiponectin: more than just another fat cell hormone? Diabetes Care, 26: 2442-50.

71. Hotta, K., T. Funahashi and Y. Arita et al., 2000. Plasma concentrations of a novel, adiposespecific protein, adiponectin, in type 2 diabetic patients. Arterioscler Thromb. Vasc. Biol., 20: 1595-9. 
72. Kubota, N., Y. Terauchi and T. Yamauchi et al., 2002. Disruption of adiponectin causes insulin resistance and neointimal formation. J. Biol. Chem., 277: 25863-6.

73. Weyer, C., T. Funahashi and S. Tanaka et al., 2001. Hypoadiponectinemia in obesity and type 2 diabetes: close association with insulin resistance and hyperinsulinemia. J. Clin. Endocrinol. Metab., 86: 1930-5.

74. Yamamoto, Y., H. Hirose and I. Saito et al., 2002. Correlation of the adipocyte-derived protein adiponectin with insulin resistance index and serum high-density lipoprotein-cholesterol, independent of body mass index, in the Japanese population. Clin. Sci. (Lond.), 103: 137-42.

75. Haque, W.A., I. Shimomura, Y. Matsuzawa and A. Garg, 2002. Serum adiponectin and leptin levels in patients with lipodystrophies. J. Clin. Endocrinol. Metab., 87: 2395.

76. Yamauchi, T., J. Kamon and Y. Ito et al., 2003. Cloning of adiponectin receptors that mediate antidiabetic metabolic effects. Nature, 423: 762-9.

77. Fruebis, J., T.S. Tsao and S. Javorschi et al., 2001. Proteolytic cleavage product of $30-\mathrm{kDa}$ adipocyte complement-related protein increases fatty acid oxidation in muscle and causes weight loss in mice. Proc. Natl. Acad. Sci. USA, 98: 2005-10.

78. Berg, A.H., T.P. Combs and P.E. Scherer, 2002. ACRP30/adiponectin: an adipokine regulating glucose and lipid metabolism. Trends Endocrinol. Metab., 13: 84-9.

79. Berg, A.H., T.P. Combs, X. Du, M. Brownlee and P.E. Scherer, 2001. The adipocyte-secreted protein Acrp30 enhances hepatic insulin action. Nat. Med., 7: 947-53.

80. Combs, T.P., U.B. Pajvani and A.H. Berg et al., 2004. A transgenic mouse with a deletion in the collagenous domain of adiponectin displays elevated circulating adiponectin and improved insulin sensitivity. Endocrinology, 145: 367-83.

81. Yamauchi, T., J. Kamon and H. Waki et al., 2001. The fat-derived hormone adiponectin reverses insulin resistance associated with both lipoatrophy and obesity. Nat. Med., 7: 941-6.

82. Addy, C.L., A. Gavrila, S. Tsiodras, K. Brodovicz, A.W. Karchmer and C.S. Mantzoros, 2003. Hypoadiponectinemia is associated with insulin resistance, hypertriglyceridemia and fat redistribution in human immunodeficiency virusinfected patients treated with highly active antiretroviral therapy. J. Clin. Endocrinol. Metab., 88: 627-36.

83. Lonnqvist, F., A. Thome, K. Nilsell, J. Hoffstedt and P. Arner, 1995. A pathogenic role of visceral fat beta 3 -adrenoceptors in obesity. J. Clin. Invest., 95: 1109-16.
84. Peiris, A.N., M.I. Hennes, D.J. Evans, C.R. Wilson, M.B. Lee and A.H. Kissebah, 1988. Relationship of anthropometric measurements of body fat distribution to metabolic profile in premenopausal women. Acta Med. Scand. Suppl. 723: 179-88.

85. Fujioka, S., Y. Matsuzawa and K. Tokunaga et al., 1991. Improvement of glucose and lipid metabolism associated with selective reduction of intra-abdominal visceral fat in premenopausal women with visceral fat obesity. Intl. J. Obes., 15: 853-9.

86. Kinlaw, W.B. and B. Marsh, 2004. Adiponectin and HIV-lipodystrophy: taking HAART. Endocrinology, 145: 484-6.

87. Tong, Q., J.L. Sankale and C.M. Hadigan et al., 2003. Regulation of adiponectin in human immunodeficiency virus-infected patients: relationship to body composition and metabolic indices. J. Clin. Endocrinol. Metab., 88: 155964.

88. Vigouroux, C., M. Maachi and T.H. Nguyen et al., 2003. Serum adipocytokines are related to lipodystrophy and metabolic disorders in HIVinfected men under antiretroviral therapy. AIDS, 17: 1503-11.

89. Dinges, W., D. Chen, I. Shimomura, Y. Matsuzawa, D. Peterson and A. Garg, 2003. Adipocytokine Levels in the Lipodystrophy Syndrome of HIV Adipocytokine Levels in the Lipodystrophy Syndrome of HIV-infected Patients. 10th Conf. on Retroviruses and Opportunistic Infections. Feb. 10-14, Boston, MA, Abstract 756.

90. Sutinen, J., E. Korsheninnikova, T. Funahashi, Y. Matsuzawa, T. Nyman and H. Yki-Jarvinen, 2003. Circulating concentration of adiponectin and its expression in subcutaneous adipose tissue in patients with highly active antiretroviral therapy-associated lipodystrophy. J. Clin. Endocrinol. Metab., 88: 1907-10.

91. Lindegaard, B., P. Keller, H. Bruunsgaard, J. Gerstoft and B.K. Pedersen, 2004. Low plasma level of adiponectin is associated with stavudine treatment and lipodystrophy in HIV-infected patients. Clin. Exp. Immunol., 135: 273-9.

92. Xu, A., S. Yin, L. Wong, K.W. Chan and K.S. Lam, 2004. Adiponectin ameliorates dyslipidemia induced by the human immunodeficiency virus protease inhibitor ritonavir in mice. Endocrinology, 145: 487-94.

93. Zhang, B., K. MacNaul, D. Szalkowski, Z. Li, J. Berger and D.E. Moller, 1999. Inhibition of adipocyte differentiation by HIV protease inhibitors. J. Clin. Endocrinol. Metab., 84: 4274-7. 
94. Lee, G., D. Mafong and M. Noor et al., 2004. HIV protease inhibitors increase adiponectin levels in HIV-negative men independent of induction of insulin resistance. 11th Conf. on Retroviruses and Opportunistic Infections. Feb. 8-11, San Francisco, CA, Abstract 705.

95. Jones, S., C. Waitt, D. Back and M. Pirmohamed, 2004. Effect of NRTI and PI on TNF-alpha and adiponectin mRNA expression in isolated subcutaneous and omental mature human adipocytes. 11th Conf. on Retroviruses and Opportunistic Infections. Feb. 8-11, San Francisco, CA, Abstract 707.

96. Vernochet, C., S. Azoulay and D. Duval et al., 2004. Ritonavir accumulates into cultured human adipocytes and alters insulin resistance related adipocytokines levels. 11th Conf. on Retroviruses and Opportunistic Infections. Feb. 8-11, San Francisco, CA, Abstract 708.

97. Ruan, H., P.D. Miles and C.M. Ladd et al., 2002. Profiling gene transcription in vivo reveals adipose tissue as an immediate target of tumor necrosis factor-alpha: Implications for insulin resistance. Diabetes, 51: 3176-88.

98. Johnson, J.A., J.B. Albu and E.S. Engelson et al., 2004. Increased systemic and adipose tissue cytokines in patients with HIV-associated lipodystrophy. Am. J. Physiol. Endocrinol. Metab., 286: E261-71.

99. Kotler, D.P., G. Ionescu and J.A. Johnson et al., 2003. Studies of adipose tissue metabolism in human immunodeficiency virus-associated lipodystrophy. Clin. Infect. Dis., 37 (Suppl. 2): S47-51.

100. Mynarcik, D.C., M.A. McNurlan, R.T. Steigbigel, J. Fuhrer and M.C. Gelato, 2000. Association of severe insulin resistance with both loss of limb fat and elevated serum tumor necrosis factor receptor levels in HIV lipodystrophy. J. Acquir. Immune. Defic. Syndr., 25: 312-21.

101. Ledru, E., N. Christeff, O. Patey, P. de Truchis, J.C. Melchior and M.L. Gougeon, 2000. Alteration of tumor necrosis factor-alpha T-cell homeostasis following potent antiretroviral therapy: Contribution to the development of human immunodeficiency virus-associated lipodystrophy syndrome. Blood, 95: 3191-8.

102. Jan, V., P. Cervera and M. Maachi et al., 2004. Altered fat differentiation and adipocytokine expression are inter-related and linked to morphological changes and insulin resistance in HIV-1-infected lipodystrophic patients. Antivir. Ther., 9: 555-64.

103. Kannisto, K., J. Sutinen and E. Korsheninnikova et al., 2003. Expression of adipogenic transcription factors, peroxisome proliferatoractivated receptor gamma co-activator 1 , IL-6 and CD45 in subcutaneous adipose tissue in lipodystrophy associated with highly active antiretroviral therapy. AIDS, 17: 1753-62.
104. Grundy, S.M., 2004. Obesity, metabolic syndrome and cardiovascular disease. J. Clin. Endocrinol. Metab., 89: 2595-600.

105. Ford, E.S., W.H. Giles and W.H. Dietz, 2002. Prevalence of the metabolic syndrome among US adults: Findings from the third National Health and Nutrition Examination Survey. JAMA, 287: 356-9.

106. Shetty, G.K., P.A. Economides, E.S. Horton, C.S. Mantzoros and A. Veves, 2004. Circulating adiponectin and resistin levels in relation to metabolic factors, inflammatory markers and vascular reactivity in diabetic patients and subjects at risk for diabetes. Diabetes Care, 27: 2450-7.

107. Yokoyama, C., X. Wang and M.R. Briggs et al., 1993. SREBP-1, a basic-helix-loop-helix-leucine zipper protein that controls transcription of the low density lipoprotein receptor gene. Cell, 75: 187-97.

108. Tontonoz, P., J.B. Kim, R.A. Graves and B.M. Spiegelman, 1993. ADD1: a novel helix-loophelix transcription factor associated with adipocyte determination and differentiation. Mol. Cell. Biol., 13: 4753-9.

109. Brown, M.S. and J.L. Goldstein, 1997. The SREBP pathway: regulation of cholesterol metabolism by proteolysis of a membrane-bound transcription factor. Cell, 89: 331-40.

110. Shimomura, I., R.E. Hammer and J.A. Richardson et al., 1998. Insulin resistance and diabetes mellitus in transgenic mice expressing nuclear SREBP-1c in adipose tissue: Model for congenital generalized lipodystrophy. Genes Dev., 12: 3182-94.

111. Bastard, J.P., M. Caron and H. Vidal et al., 2002. Association between altered expression of adipogenic factor SREBP1 in lipoatrophic adipose tissue from HIV-1-infected patients and abnormal adipocyte differentiation and insulin resistance. Lancet, 359: 1026-31.

112. Mondal, D., V.F. Larussa and K.C. Agrawal, 2001. Synergistic antiadipogenic effects of HIV type 1 protease inhibitors with tumor necrosis factor alpha: suppression of extracellular insulin action mediated by extracellular matrixdegrading proteases. AIDS Res. Hum. Retroviruses, 17: 1569-84.

113. Gougeon, M.L., E. Ledru, H. Naora, M. Bocchino and H. Lecoeur, 2000. HIV, cytokines and programmed cell death. A subtle interplay. Ann. N.Y. Acad. Sci., 926: 30-45.

114. Koutkia, P. and S. Grinspoon, 2004. HIVassociated lipodystrophy: pathogenesis, prognosis, treatment and controversies. Annu. Rev. Med., 55: 303-17.

115. Benn, P., C. Ruff and J. Cartledge et al., 2003. Overcoming subjectivity in assessing facial lipoatrophy: Is there a role for three-dimensional laser scans? HIV Med., 4: 325-31. 
116. Woerle, B., C.W. Hanke and G. Sattler, 2004. Poly-L-lactic acid: a temporary filler for soft tissue augmentation. J. Drugs Dermatol., 3: 3859.

117. Moyle, G.J., 2004. Bridging a gap: Surgical management of HIV-associated lipoatrophy. AIDS Read, 14: 472-5.

118. Jones, D.H., A. Carruthers and D. Orentreich et al., 2004. Highly Purified 1000-cSt Silicone Oil for Treatment of Human Immunodeficiency Virus-Associated Facial Lipoatrophy: An Open Pilot Trial. Dermatol. Surg., 30: 1279-86.

119. Yki-Jarvinen, H., 2004. Thiazolidinediones. N. Engl. J. Med., 351: 1106-18.

120. Maeda, N., M. Takahashi and T. Funahashi et al., 2001. PPARgamma ligands increase expression and plasma concentrations of adiponectin, an adipose-derived protein. Diabetes, 50: 2094-9.

121. Yang, W.S., C.Y. Jeng and T.J. Wu et al., 2002. Synthetic peroxisome proliferator-activated receptor-gamma agonist, rosiglitazone, increases plasma levels of adiponectin in type 2 diabetic patients. Diabetes Care, 25: 376-80

122. Phillips, S.A., T.P. Ciaraldi and A.P. Kong et al., 2003. Modulation of circulating and adipose tissue adiponectin levels by antidiabetic therapy. Diabetes, 52: 667-74.

123. Yu, J.G., S. Javorschi and A.L. Hevener et al., 2002. The effect of thiazolidinediones on plasma adiponectin levels in normal, obese and type 2 diabetic subjects. Diabetes, 51: 2968-74.

124. Spiegelman, B.M. and J.S. Flier, 1996. Adipogenesis and obesity: Rounding out the big picture. Cell, 87: 377-89.

125. Carr, A., K. Samaras, D.J. Chisholm and D.A. Cooper, 1998. Pathogenesis of HIV-1-protease inhibitor-associated peripheral lipodystrophy, hyperlipidaemia and insulin resistance. Lancet, 351: 1881-3.

126. Mooser, V. and A. Carr, 2001. Antiretroviral therapy-associated hyperlipidaemia in HIV disease. Curr. Opin. Lipidol., 12: 313-9.

127. Purnell, J.Q., A. Zambon and R.H. Knopp et al., 2000. Effect of ritonavir on lipids and postheparin lipase activities in normal subjects. AIDS, 14: 51-7.

128. Wentworth, J.M., T.P. Burris and V.K. Chatterjee, 2000. HIV protease inhibitors block human preadipocyte differentiation, but not via the PPARgamma/RXR heterodimer. J. Endocrinol., 164: R7-R10.
129. Hadigan, C., S. Yawetz, A. Thomas, F. Havers, P.E. Sax and S. Grinspoon, 2004. Metabolic effects of rosiglitazone in HIV lipodystrophy: a randomized, controlled trial. Ann. Intern. Med., 140: 786-94.

130. Gelato, M.C., D.C. Mynarcik and J.L. Quick et al., 2002. Improved insulin sensitivity and body fat distribution in HIV-infected patients treated with rosiglitazone: A pilot study. J. Acquir. Immune. Defic. Syndr., 31: 163-70.

131. Carr, A., C. Workman and D. Carey et al., 2004. No effect of rosiglitazone for treatment of HIV-1 lipoatrophy: randomised, double-blind, placebocontrolled trial. Lancet, 363: 429-38.

132. Sutinen, J., A.M. Hakkinen and J. Westerbacka et al., 2003. Rosiglitazone in the treatment of HAART-associated lipodystrophy--a randomized double-blind placebo-controlled study. Antivir. Ther., 8: 199-207.

133. Sutinen, J., K. Kannisto and E. Korsheninnikova et al., 2004. Effects of rosiglitazone on gene expression in subcutaneous adipose tissue in highly active antiretroviral therapy-associated lipodystrophy. Am. J. Physiol. Endocrinol. Metab., 286: E941-9.

134. Sutinen, J., K. Kannisto and E. Korsheninnikova et al., 2004. In the lipodystrophy associated with highly active antiretroviral therapy, pseudoCushing's syndrome is associated with increased regeneration of cortisol by 11 betahydroxysteroid dehydrogenase type 1 in adipose tissue. Diabetologia.

135. Masuzaki, H., J. Paterson and H. Shinyama et al., 2001. A transgenic model of visceral obesity and the metabolic syndrome. Science, 294: 2166-70.

136. Berger, J., M. Tanen and A. Elbrecht et al., 2001. Peroxisome proliferator-activated receptor-gamma ligands inhibit adipocyte 11 beta -hydroxysteroid dehydrogenase type 1 expression and activity. J. Biol. Chem., 276: 12629-35.

137. Tomlinson, J.W., J. Moore and M.S. Cooper et al., 2001. Regulation of expression of 11 betahydroxysteroid dehydrogenase type 1 in adipose tissue: tissue-specific induction by cytokines. Endocrinology, 142: 1982-9.

138. van Wijk, J.P., E.J. de Koning, E.P. Martens and T.J. Rabelink, 2003. Thiazolidinediones and blood lipids in type 2 diabetes. Arterioscler. Thromb. Vasc. Biol., 23: 1744-9.

139. Khan, M.A., J.V. St Peter and J.L. Xue, 2002. A prospective, randomized comparison of the metabolic effects of pioglitazone or rosiglitazone in patients with type 2 diabetes who were previously treated with troglitazone. Diabetes Care, 25: 708-11. 
140. Calmy, A., B. Hirschel, D. Hans, V.L. Karsegard and C.A. Meier, 2003. Glitazones in lipodystrophy syndrome induced by highly active antiretroviral therapy. AIDS, 17: 770-2.

141. Gavrila, A., W. Hsu and S. Tsiodras et al., 2004. Effect of Pioglitazone and/or Fenofibrate on the HIV-associated metabolic syndrome: A 2x2 factorial, randomized, double-blinded, placebocontrolled trial. Endocrine Society 86th Annual Meeting. New Orleans, Abstract.

142. Walli, R., G.M. Michl, D. Muhlbayer, L. Brinkmann and F.D. Goebel, 2000. Effects of troglitazone on insulin sensitivity in HIVinfected patients with protease inhibitorassociated diabetes mellitus. Res. Exp. Med. (Berl.), 199: 253-62.
143. Hayes, M.M., B.R. Lane, S.R. King, D.M. Markovitz and M.J. Coffey, 2002. Peroxisome proliferator-activated receptor gamma agonists inhibit HIV-1 replication in macrophages by transcriptional and post-transcriptional effects. J. Biol. Chem., 277: 16913-9.

144. Jiang, C., A.T. Ting and B. Seed, 1998. PPARgamma agonists inhibit production of monocyte inflammatory cytokines. Nature, 391: 82-6.

145. Lee JH, Chan JL, Sourlas E, Raptopoulos V, Mantzoros CS. r-metHuLeptin therapy in replacement doses improves insulin resistance and metabolic profile in patients with lipoatrophy and metabolic syndrome induced by the highly active antiretroviral therapy (HAART). J Clin Endocrinol Metab 2006; 91(7):2605-11. 